Fanum

Sociológico

\section{Forum Sociológico}

Série II

$22 \mid 2012$

Saúde e multiculturalidade

De Mercadoria a Presente, ou como uma mercadoria massificada se transforma em presente singular

Alice Duarte

(2) OpenEdition

Journals

Edição electrónica

URL: https://journals.openedition.org/sociologico/622

DOI: $10.4000 /$ sociologico.622

ISSN: 2182-7427

Editora

CICS.NOVA - Centro Interdisciplinar de Ciências Sociais da Universidade Nova de Lisboa

Refêrencia eletrónica

Alice Duarte, «De Mercadoria a Presente, ou como uma mercadoria massificada se transforma em presente singular», Forum Sociológico [Online], 22 | 2012, posto online no dia 01 março 2013,

consultado o 31 março 2022. URL: http://journals.openedition.org/sociologico/622 ; DOI: https:// doi.org/10.4000/sociologico.622

Este documento foi criado de forma automática no dia 31 março 2022.

(c) CICS.NOVA 


\title{
De Mercadoria a Presente, ou como uma mercadoria massificada se transforma em presente singular
}

\author{
Alice Duarte
}

\section{Introdução}

1 Ao longo do último século, a cultura da sociedade industrial tornou-se em grau crescente uma cultura baseada num mundo de objetos produzidos e distribuídos em massa. Ver essa tendência dominante de mercadorização, e as próprias mercadorias, como algo essencialmente negativo é o caminho mais curto para afirmações niilistas sobre a sociedade contemporânea. Pelo contrário, reconhecer que não é por serem produzidas em massa que as mercadorias estão divorciadas de considerações culturais/ morais ou podem ser removidas dos contextos socioculturais em que operam e são usadas (Appadurai, 1986: 12), essa é uma postura que conduz (e obriga) à abordagem do consumo enquanto prática cultural. Seguindo essa perspetiva, o consumo surge inquestionavelmente como um processo socializado e as mercadorias, enquanto parte integrante da cultura material da nossa sociedade, como apropriadas e personalizadas de muitos e diversos modos, desempenhando papel instrumental enquanto meios de expressão e comunicação dos sujeitos-consumidores.

Guiada pela intenção de compreender de modo aprofundado a ressocialização de que as mercadorias são alvo por parte de sujeitos concretos inseridos nos seus respetivos contextos familiares ${ }^{1}$, concebi e levei a cabo uma pesquisa de contornos francamente qualitativos, concluída em 2007 e abrangendo 24 famílias como unidades de estudo. Das múltiplas facetas da vida, pessoal e familiar, que se cruzam com o consumo e a ele recorrem enquanto meio de expressão e construção de sentidos, noutro sítio já tive oportunidade de demonstrar o quanto o consumo pode ser participante do processo de autoconstrução identitária, bem assim como um elemento-chave na caracterização das novas classes médias portuguesas ${ }^{2}$. Uma outra vertente analítica igualmente 
esclarecedora do caráter performativo do significado das mercadorias é a consideração do processo de consumo em termos da dinâmica de sociabilidade, pela qual as mercadorias são postas ao serviço da criação e manutenção das relações interpessoais dos atores. Esse consumo para os outros na forma de presentes mereceu igualmente atenção, tendo os respetivos resultados analíticos - acabados de sair em livro demonstrado com exuberância de pormenores como os bens de consumo são capazes de corporizar fluxos de sociabilidades ${ }^{3}$. A propósito desse consumo para os outros, neste artigo trata-se de sumariar alguns resultados relativos aos principais mecanismos pelos quais os laços sociais são consolidados através das mercadorias e estas se constituem como complementos relacionais dos sujeitos consumidores.

\section{Da mercadoria massificada ao presente singular}

3 Abordado enquanto prática cultural, o processo de consumo surge definido não como mero ato de compra, mas, antes, como abrangendo todos os atos e decisões anteriores e posteriores à compra propriamente dita. Procedendo à análise de tais práticas, é possível compreender e documentar as apropriações e recontextualizações singulares de bens, levadas a cabo pelos consumidores-informantes. Ao nível do consumo para os outros na forma de presentes, a análise dos atos práticos pelos quais um consumidor busca, escolhe, compra e oferece bens de consumo destinados a outra pessoa permite descortinar o processo pelo qual as mercadorias são transmutadas em presentes singulares, capazes de ligar entre si essas pessoas.

4 Importará esclarecer que os relacionamentos interpessoais considerados abrangem as redes de sociabilidades familiares, bem assim como as redes de laços sociais mais dependentes de lógicas de eletividade como os círculos de amizade, de vizinhança e profissionais. Por outro lado, quanto aos bens de consumo que cruzam a trama formada por esses relacionamentos interpessoais, a categoria de "presentes" sujeita a escrutínio analítico engloba todo o tipo de "coisas" oferecidas e/ou trocadas pelas unidades de estudo, se bem que limitando-se às suas variantes materiais. Dado que o objetivo é dar conta do papel instrumental desempenhado pelos bens na consolidação e desenvolvimento das relações interpessoais dos sujeitos, da noção de "presente" adotada ficam excluídas todas as possibilidades que não cumpram esse requisito, como sejam as ofertas em trabalho ou sob qualquer outra forma imaterial. Quanto aos circuitos de oferta e troca de presentes considerados, a análise abrange quer o circuito alargado de presentes natalícios, quer, de um modo mais geral, todos os contextos de troca de presentes, dos mais recorrentes aos mais esporádicos, em que as unidades domésticas e/ou os seus membros a título mais individual efetivamente participam.

5 A compreensão das redes de relações interpessoais ativadas e praticadas pelos informantes surgiu facilitada pela consideração do circuito alargado de presentes de Natal, dado essa ser uma altura em que, ao mesmo tempo, se presenteiam múltiplas pessoas e se é por elas presenteado, tornando-se mais percetíveis as direções e os sentidos dominantes das trocas. Porém, importa reter que quer os restantes contextos mais regulares de troca de presentes, quer as situações mais ocasionais em que se verifica a sua circulação, confirmaram a recorrência das mesmas tendências. No interior da sua enorme diversidade, todas as ocasiões surgem unidas pela repetição do predomínio flagrante das redes familiares, seguidas a alguma distância pelas de amizade, como os principais circuitos de oferta de presentes. Observados no seu 
conjunto, os movimentos de presentes tornaram absolutamente claro que a sua circulação se apresenta como um meio fundamental pelo qual os informantes procedem à atualização das respetivas redes de sociabilidade. Em simultâneo e por isso mesmo, as ofertas de presentes surgem genericamente associadas a situações, momentos e acontecimentos entendidos como agradáveis e felizes.

Os resultados alcançados através da consideração pormenorizada das práticas de consumo para os outros na forma de presentes não deixam dúvidas quanto a esta ser mais uma das modalidades pelas quais as mercadorias desempenham um papel instrumental na vida das pessoas. O domínio de consumo dos presentes corporiza práticas cuja abrangência é universal entre os agregados domésticos constituídos como unidades de estudo. Em todos eles é assinalável o acionar de consideráveis recursos materiais e imateriais, como dinheiro, tempo e empenhamentos diversos - votados à obtenção de bens de consumo para terceiros. Se alguma dúvida subsistisse quanto ao teor pessoal e familiar das estruturas de significado atuantes na ressocialização de mercadorias efetuada pelos consumidores, a consideração do domínio de consumo dos presentes seria um bom e eficaz meio de demonstrar a participação central dos afetos e dos sentimentos nos mecanismos da procura do consumo. Os rituais de troca (McCracken, 1988) concretizados e o subjacente trabalho efetivo, pelo qual se realiza a apropriação de mercadorias para um outro, fazem-se em nome, sobretudo, de sentimentos como o amor, a gratidão, a amizade, o afeto.

7 Dito isto e atendendo às limitações de espaço impostas a este texto, passo à apresentação de algumas tendências ativas consistentemente evidenciadas pela análise relativamente ao modo como as mercadorias são apropriadas e postas ao serviço da criação e manutenção das redes de sociabilidade dos sujeitos consumidores.

Em termos de dinâmicas e fluxos de sociabilidade por intermédio da circulação de presentes, os círculos familiares apresentam-se como o foco destacado, quer da origem, quer do destino dos presentes, o que deve ser entendido como um mecanismo que permite aos laços familiares autorreproduzirem o seu próprio reforço. Em simultâneo, a troca de presentes entre familiares é um meio de estruturação da intimidade dos parentes que surgem distribuídos por três círculos concêntricos distintos. Segundo o respetivo grau de parentesco, os familiares surgem distribuídos por círculos concêntricos cada vez mais afastados de troca. O primeiro e mais intenso desses círculos abrange os membros da família elementar, surgindo os filhos e os cônjuges como os destinatários privilegiados. O círculo seguinte transpõe o nível da família nuclear, em grande medida devido ao desenrolar normal do ciclo de vida desses grupos e correspondente constituição de novos lares por parte dos descendentes. Em função disso, abrange, igualmente filhos, pais e irmãos, embora residentes em espaços diferenciados, a que se juntam também novos parentes produzidos ou fruto das alianças realizadas. Neste segundo círculo, ainda que formalmente definidos como idênticos, nem todos os parentes ocupam lugares semelhantes em termos afetivos, o que é evidenciado também pela respetiva circulação de presentes. O terceiro círculo abrange tios e primos em extensão e intensidade de troca de presentes ainda mais variável, cujos contornos reproduzem as linhas de afetividade mais valorizadas em cada família.

9 Como princípio geral, foi possível verificar que, quanto mais nos aproximamos do círculo central - e por oposição quer ao terceiro círculo de parentes, quer aos circuitos de amizade -, mais a reciprocidade não é, nem é entendida como precisando de ser, estritamente simétrica (Sahlins, 1972). Em simultâneo, um outro padrão identificado 
diz respeito à circulação de presentes entre os cônjuges. Entre estes, a oferta de um presente implica, quase sempre, a sua contra-oferta simultânea, o que, sendo em si mesmo um reforço da ligação que os une, é igualmente um indício da tensão e ansiedade que essas relações interpessoais podem recobrir. Neste caso, a questão da reciprocidade, nomeadamente em termos das ocasiões de troca, torna-se especialmente importante. Atendendo às lutas e conflitos latentes que tal tendência revela, coloca-se a questão de os presentes entre cônjuges poderem elucidar igualmente sobre as relações de poder que se fazem sentir no seio da família. Tais indícios permitem pôr em causa uma noção excessivamente durkheimiana de família, demonstrando que tal grupo social não é, em exclusivo, uma unidade de interesses convergentes.

Globalmente consideradas, são bastante raras as situações em que outras pessoas ombreiam lado a lado com os familiares próximos enquanto destinatários de presentes. Uma das poucas possibilidades de isso acontecer surge com a eleição apaixonada do par amoroso. Neste caso, a família pode mesmo ser ultrapassada, tornando-se o namorado/a quase o único destino dos presentes, ou o seu principal destino através da prática de múltiplas prendas, por contraste com as ofertas singulares dos restantes destinatários. A universalidade do par amoroso como destino de prendas e o facto de, por vezes, apenas ele e os membros da respetiva família elementar serem presenteados denota a equiparação afetiva realizada entre um e os outros, sendo isso, em grande parte, concretizado e expresso pela idêntica atenção dispensada à obtenção dos respetivos presentes.

11 A outra possibilidade de algumas pessoas ocuparem um lugar de preponderância idêntica à dos membros da família enquanto destino privilegiado de presentes aparece quando os amigos surgem como categoria socioafetiva significativa, tornando-se, também eles, destinatários regulares de prendas. Neste caso, foi possível identificar o princípio geral de, aqui, a troca de presentes ser essencialmente simétrica e assente numa reciprocidade estrita e tendencialmente imediata. Ao nível das redes de amizade como origem e destino de prendas, constata-se o acentuado predomínio da reciprocidade equilibrada, caracterizada pela inexistência geral de fluxos unidirecionais (Sahlins, 1972).

12 Atendendo à circulação total de presentes, pôde ser estabelecida uma inequívoca relação entre a hierarquia de importância dos presenteados e o escalonamento financeiro das respetivas prendas. Ao nível das redes familiares, verificou-se a existência de um princípio de aplicação universal: os elementos distribuídos pelos três círculos concêntricos de parentes recebem presentes cujo valor financeiro aumenta da periferia para o centro. Os parentes mais afastados são contemplados com presentes de menor valor financeiro e o valor-limite estabelecido para essas categorias de familiares é religiosamente cumprido. Por contraste extremo, os membros da família elementar recebem sempre as prendas de maior valor financeiro e, na maioria dos casos, ou o seu valor-limite não chega a ser definido, ou, quando o é, tende a ser sistematicamente ultrapassado. $\mathrm{O}$ mesmo princípio interpretativo apresentou-se válido para todas as redes de sociabilidade consideradas. Não só os objetos materiais que são os presentes servem a expressão do amor e carinho dos informantes, como, em simultâneo, o seu valor diferenciado de custo no mercado é igualmente acionado como recurso visando a expressão de afetos e sentimentos. O mais elevado apreço sentido por uma pessoa encontra correspondência bastante direta no preço mais elevado do presente escolhido para ela. Não apenas a compra e troca de presentes servem a manifestação de afetos, 
mas também o ordenamento e as gradações desses afetos surgem reproduzidos no valor nominal diferenciado dos presentes comprados. Seguindo a mesma lógica, na situação inversa em que diferentes presenteados surgem para um dador como situados no mesmo patamar de afeto ou carinho, é procurada uma estrita equivalência financeira dos respetivos presentes. A regra é bastante clara: se o dispêndio financeiro é justificadamente variável segundo a profundidade das relações existentes, relações equivalentes em termos afetivos exigem absoluta equivalência financeira. Relativamente a posteriores investigações, será de fundamental importância o reconhecimento de que os presentes objetificam fluxos de sociabilidade, também deste modo.

13 Para além da compreensão abrangente sobre quem eram os sujeitos implicados nas práticas de consumo para os outros na forma de presentes, a análise realizada permitiu igualmente elucidar sobre os processos de apropriação pelos quais as mercadorias são transformadas em presentes singulares e específicos, mediadores de relações interpessoais concretas. Orientando a atenção para o processo de seleção e obtenção dos bens oferecidos foi possível alcançar alguns princípios interpretativos, de consistência bastante sólida, sobre o modo como as mercadorias são utilizadas enquanto mediadores de relacionamentos interpessoais.

14 A análise transversal da totalidade do material empírico permitiu compreender que, em termos gerais, os presentes trocados tendem a caber no que designei por luxo utilitário. Com esta noção procurei traduzir o facto de, idealmente, um presente dever ser utilizável e efetivamente utilizado pelo destinatário, mas sem cair no estritamente utilitário, no sentido de necessariamente dever comportar um qualquer extra, de modo a não ser absolutamente idêntico ao comprado no quotidiano por qualquer um. 0 presente a oferecer não pode ser algo completamente prosaico, devendo conter em si uma dimensão de exceção pela qual a ligação entre as pessoas envolvidas surge materializada e, assim, manifesta. ${ }^{4} \mathrm{~A}$ máxima "oferecemos aquilo que nunca chegamos a comprar para nós mesmos" reenvia em simultâneo para essa dimensão de exceção que se entende que um presente deve corporizar e para a relação subjacente que justifica o carácter excecional desse comportamento.

15 Quanto aos processos de apropriação criativa pelos quais os bens são transformados em veículos de sociabilidades, um princípio central identificado é o da individualização dos presentes. Porque uma pessoa a presentear é, para o dador, não um ser isolado, mas um ser integrado numa determinada rede relacional onde ocupa uma posição devidamente hierarquizada; porque, além dessa posição relativa resultante de considerações mais pessoais e afetivas, a mesma pessoa a presentear deve também ser equacionada em termos do código de presentes socialmente existente; e porque o objetivo último do dador é sempre conseguir que o presente escolhido seja apreciado e do agrado do destinatário, a seleção e aquisição de um presente faz-se tendo em mente destinatários específicos. Pela ponderação de todos estes fatores e correlativos atos práticos concretiza-se um trabalho de apropriação capaz de transformar objetos anónimos produzidos em massa não só em objetos singulares, mas também em veículos de manutenção e reforço das relações existentes entre os sujeitos envolvidos.

Mas defender que os presentes são pensados e comprados tendo em vista um destinatário específico não é o mesmo que defender que a seleção de uma prenda nunca sofra desatenções ou seja concretizada em todas as ocasiões e para os diferentes destinatários com um mesmo elevado grau de empenhamento. Importa reter, então, 
que o princípio do destinatário específico é desdobrado na seguinte regra de aplicação geral: os esforços efectivamente disponibilizados na obtenção dos presentes variam em função das relações afetivas e sociais estabelecidas pelo dador com cada um dos destinatários particulares dos seus presentes. Tais esforços, que incluem o empenho monetário, mas também o zelo, o tempo e a energia despendidos na procura e seleção dos presentes, refletem o empenhamento diferenciado que cada relacionamento exige para se manter ou renovar. Um nível elevado de esforços remete para relações e destinatários entendidos como merecedores de especial atenção afetiva, amorosa ou social. É neste sentido que as relações existentes entre as pessoas são, de facto, mediadas pelos objetos comprados e oferecidos. Os presentes, e todo o trabalho a que a sua obtenção obriga, objetificam os sentimentos que ligam as pessoas implicadas em cada relação concreta. Bens materiais e sentimentos são intercomunicáveis, surgindo os primeiros como uma ferramenta de manutenção e reforço dos relacionamentos existentes.

Entretanto - em paralelo com o grau diferenciado de empenhamento segundo os destinatários e o correlativo desempenho dos presentes como efetivos mediadores das relações entre dadores e destinatários - é igualmente notório que a individualização dos presentes se constitui em representação cultural dominante, sendo percetível uma certa idealização culturalmente sustentada dessa atitude. O reconhecimento e a proclamação da importância da individualização dos presentes são um tópico discursivo sempre e unanimemente reiterado pelos informantes, sem que atendam aos matizes de comportamento efetivamente concretizados. $\mathrm{O}$ facto de, discursiva e idealmente, tais matizes não existirem, torna claro que para os informantes o trabalho de consumo (Miller, 1987) e correlativo processo de apropriação são percebidos como fundamentais, surgindo claramente relacionados com a possibilidade de os presentes mediarem ligações efetivas entre as pessoas.

Em termos das dimensões mais práticas dos processos de apropriação dos bens de consumo para oferta, a análise compreensiva realizada foi capaz de fornecer um quadro vivo e rico de pormenores. O extenso processo de apropriação e suas múltiplas manifestações - conducentes à obtenção de um presente adequado - surpreendem pela intrincada mistura de sentimentalismo e pragmatismo. $O$ ritual de troca e correlativa transferência de significado (McCracken, 1988) da mercadoria para o destinatário através do respetivo dador - ligando os três de um modo particular - obriga ao cumprimento de um conjunto de atos práticos que implicam doses significativas de trabalho concreto e de imaginação. A expressão de sentimentos como o amor, o carinho, a gratidão por intermédio de bens materiais exige, de forma objetiva, o cumprimento de tarefas como: conceber o que seja o presente "certo" para a situação e sujeito em questão; coletar de forma mais ou menos sub-reptícia informações diversas, recolhidas com o auxílio de várias pessoas, sobre algum especial desejo ou necessidade de momento dos futuros destinatários e, constantemente, cruzar e atualizar essas informações sem a desconfiança daqueles; percorrer espaços comerciais e lojas específicas, muito provavelmente através de várias rondas de prospeção antes da compra efetiva; ponderar em termos definitivos a seleção a efetuar sem deixar de atender também quer às novidades, quer aos respetivos limites orçamentais; assegurar a adequação do respetivo embrulho. O grau de atenção latente continuamente manifestada a propósito da obtenção de presentes torna legítima a perceção de que as atividades de consumo para os outros são sustentadas por doses significativas de canseira, trabalho, tempo e dinheiro. Perante o grau de dificuldade que parece ser 
inerente à obtenção dos bens de consumo para oferecer como presentes, quase se poderia duvidar de que o contexto de fundo fosse o da "sociedade de consumo" e correspondente abundância de mercadorias.

o cuidado atento que pretendo fazer entender como componente flagrante das atividades de consumo para os outros pode ser ilustrado de forma emblemática pelo que designei como tabu do preço. De forma unânime e consciente, todos os informantes se esforçam para que o preço do presente seja retirado do respetivo objeto, eliminandose assim o acesso direto do destinatário a tal informação. 0 caráter simbólico do tabu do preço é evidente, já que, em termos aproximados, normalmente qualquer pessoa tem noção do valor de custo dos presentes recebidos e, quando tal não acontece, existem possibilidades muito reais de facilmente o ficar a conhecer, se tal for desejado. Contudo, esse é mais um elemento do processo de apropriação do presente pelo qual este é retirado do mundo dos objetos disponibilizados no mercado e transformado numa peça que liga as duas pessoas implicadas na relação. Deste modo, o tabu do preço é útil na confirmação do quanto a relação interpessoal se encontra longínqua de uma racionalidade estritamente comercial. Mais um gesto de cuidado atento que radica a sua existência no desejo de manter separadas (e inconfundidas) as estruturas públicas de significado - que lidam, nomeadamente, com o valor monetário das coisas - e as estruturas privadas - onde os presentes são mediadores das relações afetivas e emocionais daquelas pessoas concretas.

Todavia, em simultâneo, é igualmente constatável uma certa ambivalência quanto à explicitação do esforço financeiro subjacente à oferta de qualquer presente. Porque, como se viu, o próprio dispêndio financeiro é justificadamente variável segundo a profundidade das relações existentes, são igualmente acionados esforços para assegurar que o destinatário não procede a nenhuma subavaliação do preço do presente recebido. Por isso, em paralelo com o tabu do preço, as pessoas procuram certificar-se de que os destinatários dos seus presentes têm uma ideia justa, ou até inflacionada, do valor no mercado do objeto que lhes é oferecido. Porque o contrário disso - a subavaliação do seu valor de custo ou o pressupor que se recebeu um "presente barato" - poderia ser entendido como traduzindo um desinteresse ou um descuido pelo respetivo destinatário. Portanto, a própria natureza valiosa do objeto em termos financeiros - o facto de ser um "presente caro" - não é irrelevante, devendo ser considerada, também, como mecanismo de individualização da prenda e de reforço da relação.

\section{Comentário Final}

21 No seu conjunto, os comentários acabados de produzir permitem evidenciar alguns dos procedimentos operativos através dos quais as mercadorias se tornam efetivos complementos relacionais dos atores. A este nível das atividades de consumo para os outros na forma de presentes, as interpretações analíticas enunciadas visaram evidenciar sobretudo um princípio atuante fundamental. No correspondente processo de apropriação de mercadorias concretizado pelos consumidores, a dedicação e o trabalho efetivo votados à obtenção de presentes surgem como componentes centrais e incontornáveis. $O$ extenso trabalho de consumo realizado pelas pessoas constitui-se como um meio instrumental fundamental de manutenção e reforço das suas redes de sociabilidades, pelo contributo insubstituível que presta na obtenção de presentes 
capazes de ligar - satisfatoriamente e de acordo com as expectativas pessoais e sociais as duas pessoas, ou os dois lares, implicados no respetivo ritual de troca.

Qualquer leitura da sociedade e cultura contemporâneas facilmente reconhece o grau crescente da sua mercadorização. A abordagem do consumo como prática cultural permite uma compreensão penetrante do caráter performativo do significado dos bens. Este vai variando de acordo com as situações, os tempos e os espaços em que os sujeitos os manipulam, sendo pertinente, nomeadamente, o seu equacionamento em termos da comunicação e expressão de valores. No interior de uma conceção do consumo como conjunto de práticas social e pessoalmente significantes, pelas quais são concretizadas apropriações criativas por parte dos sujeitos, a ressocialização das mercadorias enquanto mediadores de relacionamentos interpessoais é indubitavelmente um tópico que merece ser equacionado. A compreensão dos significados culturais do consumo resulta aumentada pela análise pormenorizada do processo de consumo enquanto idioma posto ao serviço do desenvolvimento e consolidação das redes de sociabilidades.

A pesquisa compreensiva realizada e sustentadora das interpretações apresentadas ratificou de um modo bastante flagrante e vivo o assumido pressuposto de que as pessoas e as coisas, mesmo na nossa sociedade industrial, não são entidades de modo nenhum inconciliáveis. Urge tornar banal o reconhecimento de que per se os bens de massa não podem ser nem positivos nem negativos. Compreender o impacto do consumo implicará atender aos fundamentos sociais e pessoais da procura, dando conta das variações nos modos de posse e uso dos bens. Reclama-se a perspetivação da esfera do consumo como um mundo pragmático, no qual se podem observar múltiplos processos de criação de valor.

\section{BIBLIOGRAFIA}

APPADURAI, A. (1986), "Introduction: commodities and the politics of value", in A. Appadurai (ed.), The Social Life of Things: Commodities in Cultural Perspective, Cambridge, Cambridge University Press, 3-63.

CARRIER, J. (1993), “The Rituals of Christmas Giving”, in D. Miller (ed.), Unwrapping Christmas, Oxford, Oxford University Press, 55-74.

DUARTE, A. (2009), Experiências de Consumo: Estudos de Caso no Interior da Classe Média, Porto, UP Editorial.

DUARTE, A. (2011), o Consumo para os Outros: Os Presentes como Linguagem de Sociabilidade, Porto, UP Editorial.

GODBOUT, J. T. \& Caillé, A. (1992), L’Esprit du Don, Paris, Éditions La Découverte.

McCRACKEN, G. (1988), Culture and Consumption, Bloomington, Indiana University Press.

MILLER, D. (1987), Material Culture and Mass Consumption, Oxford, Basil Blackwell.

SAHLINS, M. (1972), Stone Age Economics, Londres, Tavistock. 


\section{NOTAS}

1. Uso o termo "ressocialização" para referir a transposição de uma apropriação, mais social ou colectiva accionada sobre as mercadorias, para uma outra apropriação, mais específica e diferenciada das mesmas mercadorias.

2. Duarte, Alice (2009). Experiências de Consumo: Estudos de Caso no Interior da Classe Média, Porto, UP Editorial.

3. Duarte, Alice (2011). O Consumo para os Outros: Os Presentes como Linguagem de Sociabilidade, Porto, UP Editorial.

4. J. Carrier (1993: 60) nota a prevalência da ideia de que os presentes "não devem ser muito úteis", defendendo que "frívolos, luxuosos ou especiais são formas de os distinguir das utilidades comuns que se compram rotineiramente". Ainda que não exatamente a propósito dos presentes, mas do dom em geral, Godbout e Caillé (1992: 70) defendem que este é acompanhado de um pouco de delapidação, de excesso e de loucura.

\section{RESUMOS}

Ao longo do último século, a cultura da sociedade industrial tornou-se crescentemente uma cultura baseada num mundo de objetos produzidos e distribuídos em massa. Através de uma abordagem do consumo como prática cultural, este artigo evidencia alguns dos mecanismos pelos quais as mercadorias são postas ao serviço da criação e manutenção das redes de sociabilidade dos sujeitos consumidores. Sistematizando as apropriações dos atores sociais relativas ao consumo para os outros, clarifico alguns dos procedimentos pelos quais os bens de consumo ligam entre si quem os compra e quem os recebe na forma de presentes. $O$ material analisado resulta de uma investigação de design francamente qualitativo, concluída em 2007, que abrangeu os rituais de troca acionados por 24 famílias residentes na cidade do Porto ou área circundante num raio de 50 quilómetros. Atendendo à totalidade das situações de oferta e receção de presentes das famílias e dos seus membros, clarifica-se como os bens de consumo são utilizados enquanto mediadores de relacionamentos interpessoais.

Over the last century, the culture of industrial society has become increasingly based in a world of objects massively produced and distributed. Through an approach of the consumption as a cultural practice, this article highlights some of the mechanisms by which the commodities are placed at the service of creating and maintaining sociability networks of the consumers. Systematizing the appropriations of the social actors concerning the consumption for others, I clarify some of the procedures by which goods interconnect who buys them and who receives them as gifts. The analysed data was obtained from a qualitative design study, completed in 2007, that included the exchange ritual operated by 24 families dwelling in Oporto city or 50 Kilometres surroundings. Given the totality of the circumstances of offer and receipt of gifts from family and its members, it is clarified how goods are used as mediators of interpersonal relationships. 
ÍNDICE

Keywords: consumption, gif, exchange ritual, sociability networks

Palavras-chave: consumo, presente, ritual de troca, redes de sociabilidade

\section{AUTOR}

\section{ALICE DUARTE}

Antropóloga. Instituto de Sociologia/Faculdade de Letras - Universidade do Porto (alice_duarte@hotmail.com) 